\title{
Analysis of the Operational Impact of ETC Lanes on Toll Station
}

\author{
Alimam Mohammed Karim ${ }^{*}$, Alimam Mohammed Abdellah, Seghiouer Hamid
}

MOSIL, University Abdelmalek Essaadi, 93000, Morocco

A R T I C L E I N F O

Article history:

Received: 15April, 2020

Accepted: 10 October, 2020

Online: 16 December, 2020:

\section{Keywords:}

ARENA

Electronic toll collection

Highway

Toll plaza

Trafic congestion

\begin{abstract}
A B S T R A C T
Traffic congestion is being experienced daily by many travellers both on the inner-city roads as well as on the highways. The toll plaza can become a real highway bottleneck, as vehicles must stop and manually pay the tolls at the toll booths. This stop-and-go process can seriously affect traffic fluidity, resulting in a lower quality of service at the plaza. One of the solutions used to improve the efficiency of toll plazas operation was the implementation of electronic toll collection (ETC), where vehicles can pass through the tolls without having to stop. In this research, a model that evaluates the benefits of the ETC system was developed using ARENA, a microscopic simulation tool. These benefits were visualized by conducting a comparative analysis of different scenarios. The Bouznika toll plaza, one of the major toll highways in Morocco, was selected for illustrating the improved operation realized from the use of ETC technology.
\end{abstract}

\section{Introduction}

One of the main causes of traffic jams on freeways is resulted from the conventional toll collection at toll gates, where each vehicle is required to stop to pay toll fees. The process of stopping to pay the toll reduces the traffic flow, increases the waiting time, queue length and thus reduces the efficiency of the toll plazas.

Therefore, in order to improve the level of service of toll plazas, a new technology has been introduced: The Electronic Toll Collection (ETC) Systems. These systems make it possible to pass through tolling location without being required to stop, and that it is thanks to a vehicle-mounted transponder that allows to uniquely identify each vehicle and to electronically collect the tolls.

With the development of ETC systems, various studies have been proposed to evaluate its performance and impacts.

Burris and Hildebrand had developed a discrete-event simulation model to examine the effect of ETC on traffic operations at the Halifax-Dartmouth Bridge in Nova Scotia, Canada. They simulated various scenarios of toll plaza configurations with and without ETC [1].

In [2], the authors used the INTEGRATION simulation model to study the impacts of ETC deployment on toll station at the Massachusetts Turnpike in Boston. Different scenarios were evaluated, and the simulation results showed an increase in the efficiency of traffic operations with the implementation of ETC. Throughput volumes, average queue length, and average waiting time spent in the system were used as measures of effectiveness.
Anthony A. Saka used a microscopic simulation model to evaluate the benefits resulting from the use of ETC technology by undertaking a comparative analysis of traffic operation condition before and after the ETC implementation [3] .

David Levinson and Elva Chang developed a model to maximize social welfare associated with toll stations. A payment choice model was used to estimate the share of traffic using ETC as a function of delay, price, and a fixed cost of acquiring the in-vehicle transponder [4].

Lu Jian made a qualitative analysis on the impacts of ETC and developed the performance index system of ETC benefits (2003) [5] . Jia Hong-fei estimated the monetary benefits of implementing ETC projects under different traffic volume conditions by using a cost-benefit analysis method [6].

Following this introductory section, a description of the proposed methodology is provided. Simulation results and performance evaluation are introduced in section 3. Finally, concluding remarks are stated in section 4 .

\section{Methodology}

\subsection{Study site selection}

The selected study site is the Bouznika toll plaza. This plaza is one of the major toll highways in Morocco. It is located on the motorway axis that connects Casablanca, the nerve center of Mo-

*Corresponding Author: Alimam Mohammed Karim, Morocco, Tangier, karim.alimam@gmail.com 
rocco's economic activity, to Rabat, the administrative capital of the country. This is the busiest section of the country's highways, with a throughput volume that could approach 50000 vehicles per day during peak periods.

The configuration of the toll facility consisted of nine manual lanes, two automated lanes and four ETC lanes.

\subsection{Data collection and analysis}

Data collection consisted of two major activities: (1) collection of service time (i.e., the time required to pay the toll and cross the barrier) data and (2) collection of traffic arrivals at the toll plaza [7]-[9].

The service time may be affected by a number of factors, such as the amount to be paid, the experience of the toll collector, the method of payment and the type of vehicle being serviced.

To determine service time distribution, we collect data over a given period of observation time. We record the time when the vehicle stops to pay the toll and the time after it crosses the toll barrier.

ARENA's Input Analyzer was used to find a probability distribution that best fits to the collected data. It is a tool designed to adjust theoretical distributions to observed data by estimating their parameters and measuring the quality of their adjustment.

With a sample size of 65 observations, we found that the service time distribution is $5.5+\operatorname{Logn}(16.7,16.8)$ for the manned tollbooths and a triangular distribution with parameters 8,10 and 12 for the automatic toll lanes (See figures 1 and 2). As for the ETC lanes, we assume an average toll transaction time of five seconds.

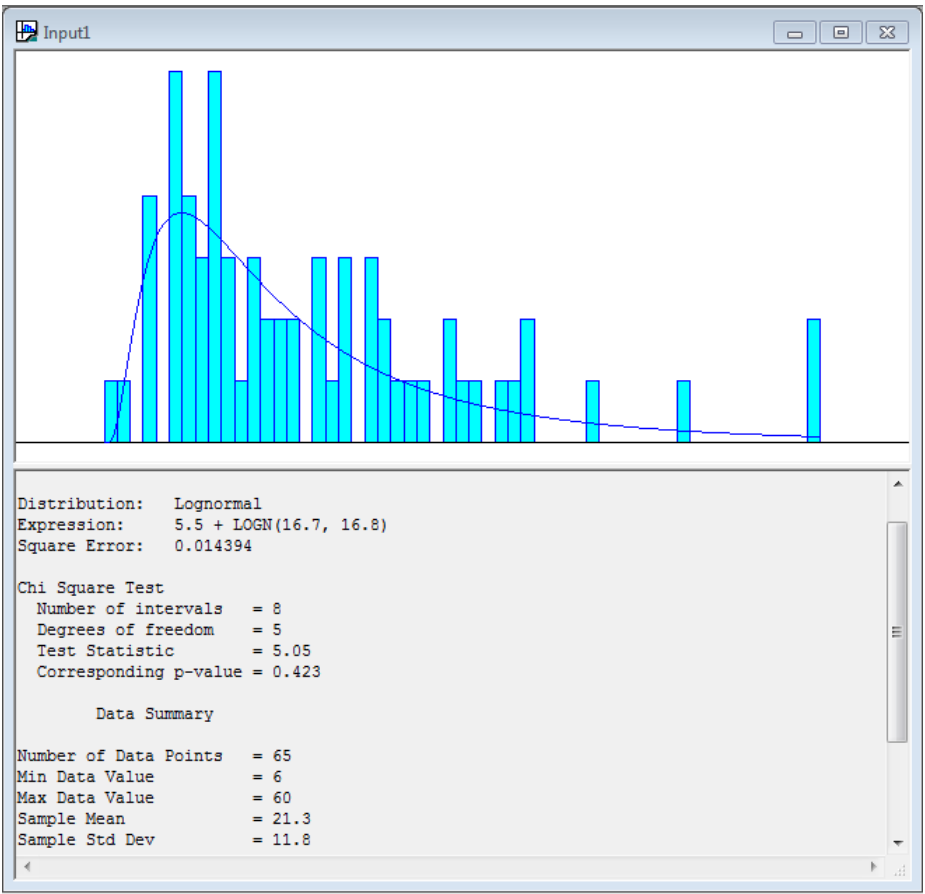

Figure 1: Results obtained for the service time distribution(Manual Tollbooth).

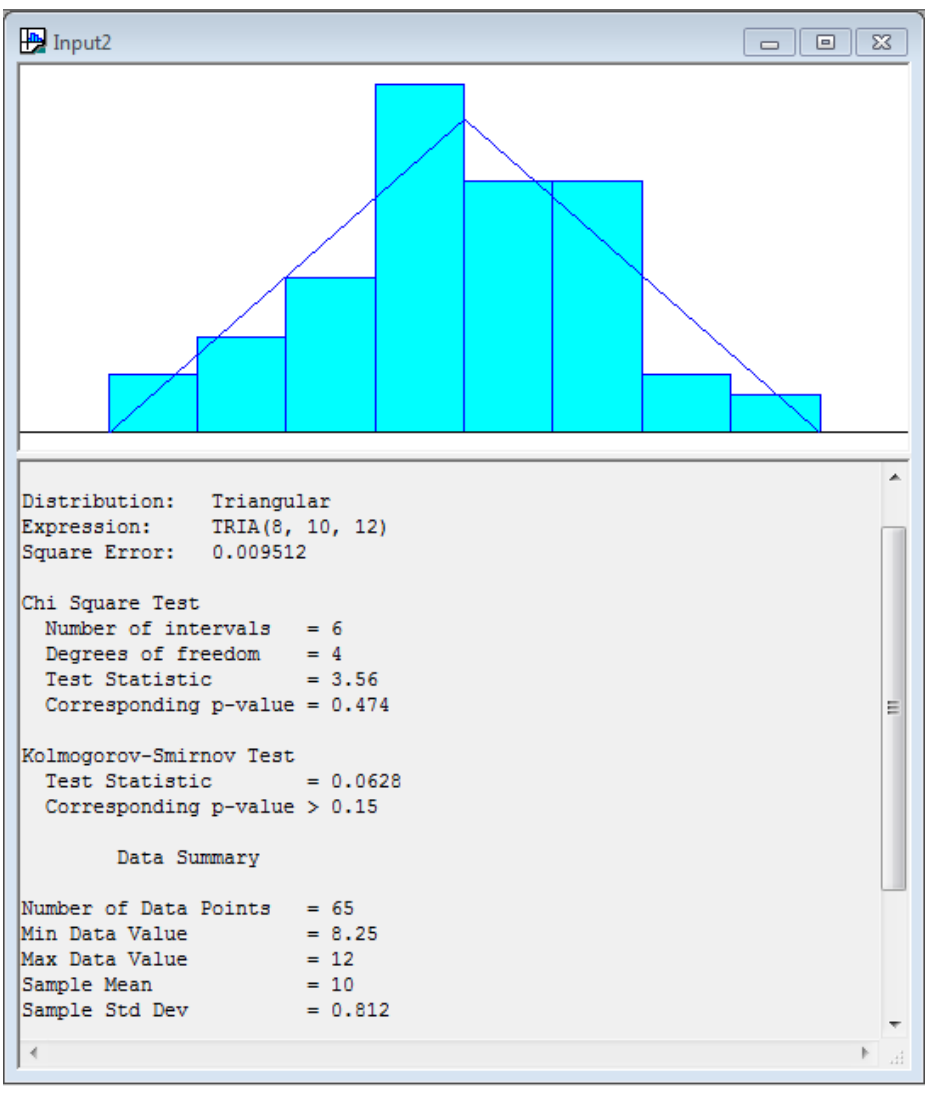

Figure 2: Results obtained for the service time distribution(Automatic Toll Lanes).

\subsection{Model development}

Simulation modelling provides a better understanding of the dynamic behaviour of systems, allows the user to compare different configurations and evaluate performance.

By using simulation, it is possible to analyse each of the system's component and to measure their relative impact on the overall performance of the system.

In our case, we use simulation in order to evaluate the impact of ETC on toll station. This evaluation was accomplished by utilizing collected field data and simulated scenarios using ARENA software. Arena is the most widely used discrete event simulation software in the world. It contains all the resources for modelling, process representation, statistical analysis and results analysis.

Furthermore, it combines the capabilities of simulation language in an integrated graphic environment, allowing for an easy user interface for model building.

Although the software was not specifically designed for toll plazas, its functionalities enable the user to model practically any type of process. It covers all discrete flows, all basic process functions: time, resources, information... at a very detailed level.

Arena provides a considerable number of statistics, automatically generated after each run, that estimate the performance measures of the system under study. These statistics are related to various components in the model, such as entities (Number in, number out, average total time in system...), resources (utilization, average number of busy resource units, number of times seized), queues (average queue delay, average queue size and minimal and 
maximal observed values), and so on [10].

To construct this model, a great deal of empirical data were required, particularly traffic volumes, service time distribution, number of lanes and percentage of vehicles using each payment option.

Figure 3 shows the flow chart of the simulation model.

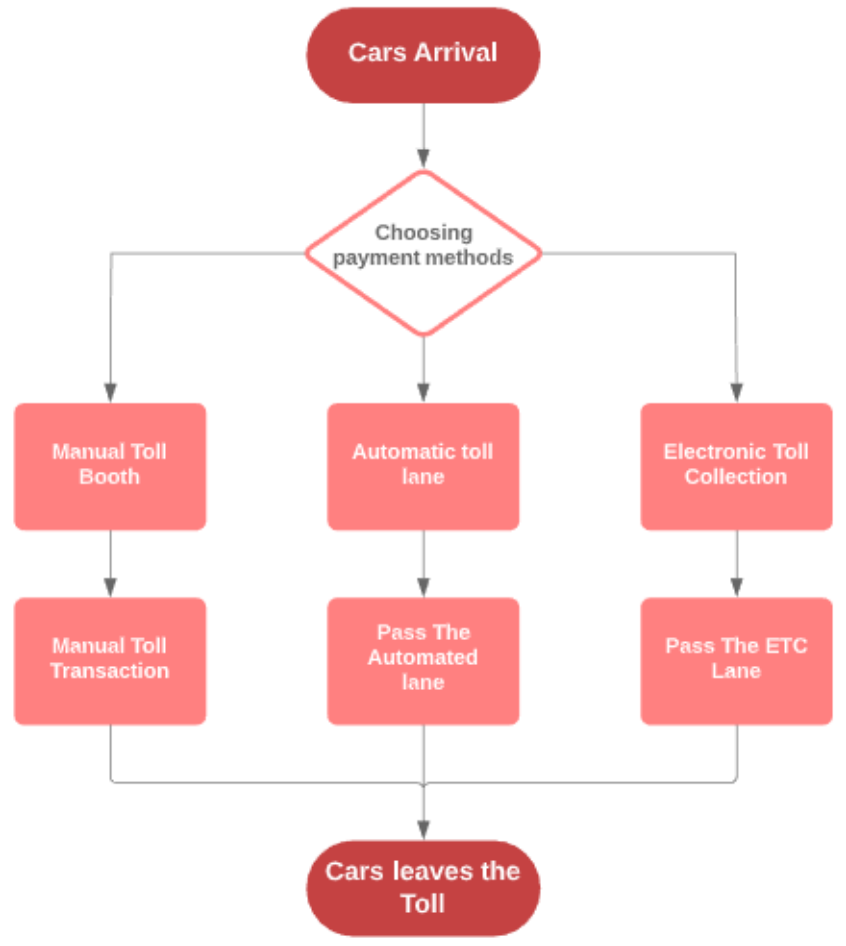

Figure 3: Simulation Flow Chart.

The simulation begins with the generation of entities (vehicles) according to a non-homogenous Poisson distribution.

The Poisson process is one of the most widely used counting processes. It is usually used in scenarios where we are counting the occurrences of certain events that appear to happen at a certain rate, but completely at random (without a certain structure).

A counting process is called a Poisson process if the following conditions hold:

- The number of entities that arrive in one interval is independent of the number of entities that arrive in any other non-overlapping interval.

- The number of occurrences in each interval can range from zero to infinity.

- The rate at which arrivals occur does not change over time.

If we look at our case study, only the two first conditions are true. In this case, we have a non-homogeneous Poisson process. Such a process has all the properties of a Poisson process, except for the fact that its rate is a function of time, which is the case for traffic arrival rate.

The traffic arrival rate varies over the course of the day, and is expressed in vehicles per hour. For the simulation, we used the hourly traffic volume obtained from the prediction results for the year 2030.
These traffic arrival rates are given in 1

Table 1: Traffic arrival rates (vehicles per hour)

\begin{tabular}{|c|c|}
\hline Hours & Traffic \\
\hline 1 & 1477 \\
\hline 2 & 1160 \\
\hline 3 & 930 \\
\hline 4 & 730 \\
\hline 5 & 802 \\
\hline 6 & 797 \\
\hline 7 & 1160 \\
\hline 8 & 1576 \\
\hline 9 & 1865 \\
\hline 10 & 2300 \\
\hline 11 & 2670 \\
\hline 12 & 3184 \\
\hline 13 & 3489 \\
\hline 14 & 3419 \\
\hline 15 & 3426 \\
\hline 16 & 3419 \\
\hline 17 & 4202 \\
\hline 18 & 4487 \\
\hline 19 & 5155 \\
\hline 20 & 5238 \\
\hline 21 & 6034 \\
\hline 22 & 5116 \\
\hline 23 & 4507 \\
\hline 24 & 2860 \\
\hline
\end{tabular}

Once generated, the vehicles were sent to either an ETC lane, automated lanes or manual lanes according to the rate of each payment option (The percentage of automated lanes users is fixed at $0.5 \%$ ). Each vehicle would then join the queue that has the shortest length in its category and waited to be served. Once the toll lane become empty, the vehicle is serviced and sent to a model block where it exited simulation. Each vehicle was tracked from its creation in the model to its destruction, and statistics were recorded throughout the vehicle's evolution.

\subsection{Model calibration and validation}

The calibration and validation process consists of adjusting the input parameters for the simulation model in order to achieve reasonable correspondence between field data and simulation model output.

The input parameters for our simulation model are arrival rate (vehicles per hour) and service time. The arrival process follows a non-homogenous Poisson distribution and the service time follows a lognormal distribution.

The average waiting time at the toll plaza was selected as the measure of effectiveness of the model (index of comparison), which is part of the simulation output data.

The purpose of this study was to evaluate the performance of the toll plaza during heavy traffic conditions. Therefore, we started by configuring the model based on the data recorded on the busiest day for traffic of the year 2019. 
Unfortunately, the waiting times at the toll plaza on this particular day are not available. We therefore decided to compare the model outputs with expert judgment, which indicate that the simulation results are relatively realistic.

\section{Results and analysis}

Scenarios with various ETC rates were simulated in order to evaluate the impact of electronic tolling system on toll plaza efficiency. Measures such as queue delay, queue length and capacity were observed when comparing the different scenarios.

Table 2 shows the experimental design of scenarios. Each scenario was simulated for 24 hours (a weekend : a sunday).

The figures 4, 5, 6 and 7 show the performance measures for the following four scenarios. They were summarized in terms of maximum, minimum, and average of queue length and waiting time.

The Queues section provide statistics for each of the fifteen toll-

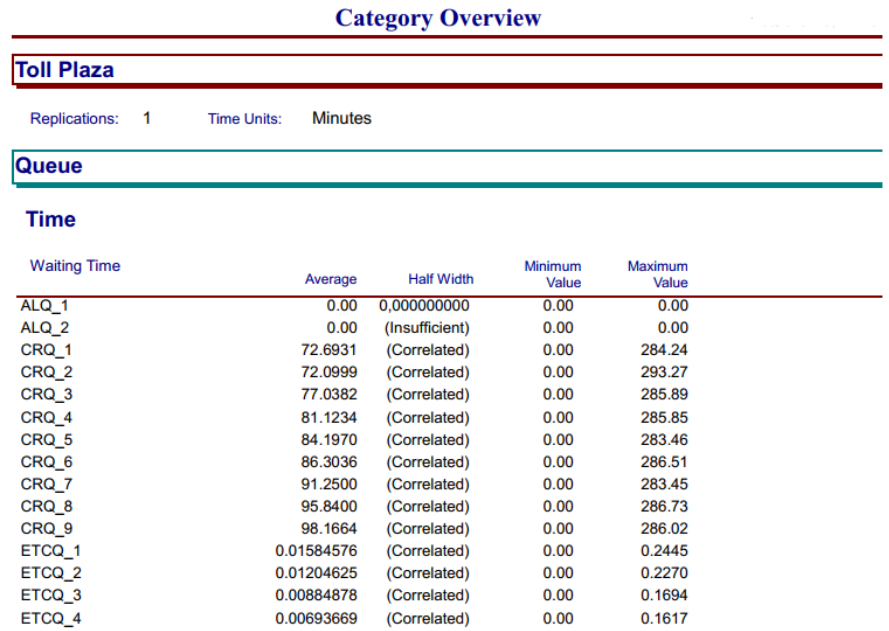

(a) Waiting time booth queues (nine cash receipt $\mathrm{CR}$ queues, two automated lanes $\mathrm{AL}$ queues and four electronic collection EC queues), such as average queue delay and average queue size.

As expected, in the case of manual service, the delay is longest compared to the ETC service. Increasing the ETC rate, without changing the configuration of the toll facility, has a direct effect in decreasing the queue length and the waiting time of the manned tollbooths, but on the other hand it increases the waiting time at the ETC lanes.

So we need to find a reasonable number of tollbooths for each payment method, considering different values of ETC rates, that minimizes the total time drivers spend waiting in the toll plaza [11]-[13].

The first scenario: We will consider a tolerable waiting time of 7 minutes and an ETC rate of $40 \%$.

By adjusting the number of booths, the maximum value of total average waiting time obtained is 7 minutes, which happens when the number of active tollbooths is 22: 18 manual lanes, 3 ETC lanes

\begin{tabular}{|c|c|c|c|c|}
\hline Number Waiting & Average & Half Width & $\begin{array}{l}\text { Minimum } \\
\text { Value }\end{array}$ & $\begin{array}{c}\text { Maximum } \\
\text { Value }\end{array}$ \\
\hline$\overline{\mathrm{ALQ}}$ 1 & 0.00 & (Insufficient) & 0.00 & 0.00 \\
\hline ALQ_2 & 0.00 & (Insufficient) & 0.00 & 0.00 \\
\hline CRQ_1 & 344.72 & (Correlated) & 0.00 & 1483.00 \\
\hline $\mathrm{CRQ}_{2} 2$ & 344.64 & (Correlated) & 0.00 & 1483.00 \\
\hline $\mathrm{CRQ}_{-}^{-3}$ & 344.57 & (Correlated) & 0.00 & 1483.00 \\
\hline CRQ_4 & 344.50 & (Correlated) & 0.00 & 1483.00 \\
\hline CRQ_5 & 344.41 & (Correlated) & 0.00 & 1483.00 \\
\hline CRQ_6 & 344.34 & (Correlated) & 0.00 & 1483.00 \\
\hline $\mathrm{CRQ}_{-}^{-7}$ & 344.27 & (Correlated) & 0.00 & 1483.00 \\
\hline CRQ_8 & 344.20 & (Correlated) & 0.00 & 1483.00 \\
\hline CRQ_9 & 344.13 & (Correlated) & 0.00 & 1482.00 \\
\hline ETCQ_1 & 0.1160 & (Correlated) & 0.00 & 3.0000 \\
\hline ETCQ_2 & 0.06580262 & (Correlated) & 0.00 & 3.0000 \\
\hline ETCQ_3 & 0.03451640 & (Correlated) & 0.00 & 3.0000 \\
\hline ETCQ_4 & 0.01832924 & (Correlated) & 0.00 & 2.0000 \\
\hline
\end{tabular}

(b) Number waiting

Figure 4: Performance indicators: Scenario 1.

Category Overview

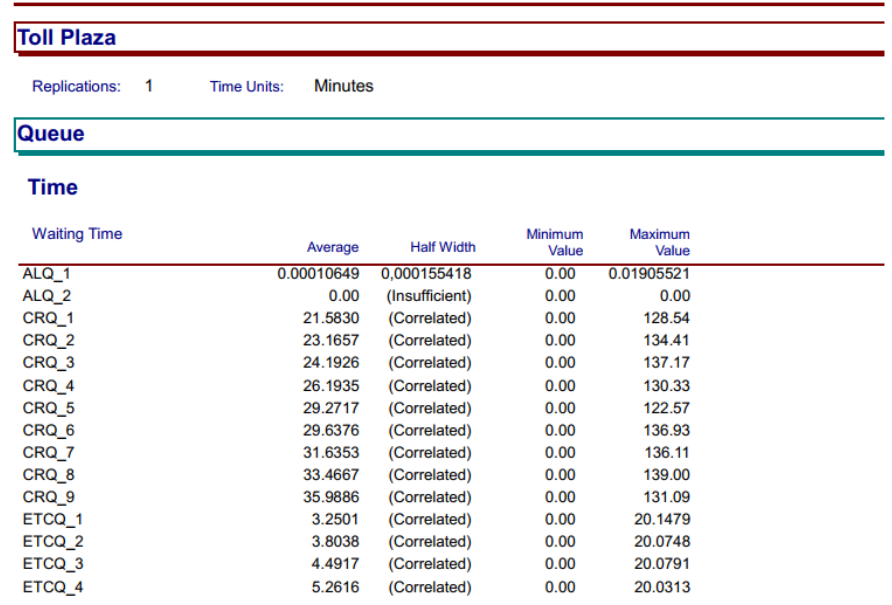

(a) Waiting time

\begin{tabular}{|c|c|c|c|c|}
\hline Number Waiting & Average & Half Width & $\begin{array}{c}\text { Minimum } \\
\text { Value }\end{array}$ & $\begin{array}{c}\text { Maximum } \\
\text { Value }\end{array}$ \\
\hline$\overline{\text { ALQ_1 }}$ & 0.00002381 & (Insufficient) & 0.00 & 1.0000 \\
\hline ALQ_2 & 0.00 & (Insufficient) & 0.00 & 0.00 \\
\hline CRQ_1 & 70.6170 & (Correlated) & 0.00 & 403.00 \\
\hline CRQ_2 & 70.5391 & (Correlated) & 0.00 & 403.00 \\
\hline CRQ_3 & 70.4706 & (Correlated) & 0.00 & 403.00 \\
\hline CRQ_4 & 70.4142 & (Correlated) & 0.00 & 402.00 \\
\hline CRQ_5 & 70.3592 & (Correlated) & 0.00 & 402.00 \\
\hline CRQ_6 & 70.3027 & (Correlated) & 0.00 & 402.00 \\
\hline CRQ_7 & 70.2541 & (Correlated) & 0.00 & 402.00 \\
\hline CRQ_8 & 70.1953 & (Correlated) & 0.00 & 402.00 \\
\hline CRQ_9 & 70.1430 & (Correlated) & 0.00 & 402.00 \\
\hline ETCQ_1 & 29.3340 & (Correlated) & 0.00 & 242.00 \\
\hline ETCQ_2 & 29.2129 & (Correlated) & 0.00 & 241.00 \\
\hline ETCQ_3 & 29.1274 & (Correlated) & 0.00 & 241.00 \\
\hline ETCQ_4 & 29.0338 & (Correlated) & 0.00 & 241.00 \\
\hline
\end{tabular}

(b) Number waiting

Figure 5: Performance indicators: Scenario 2. 


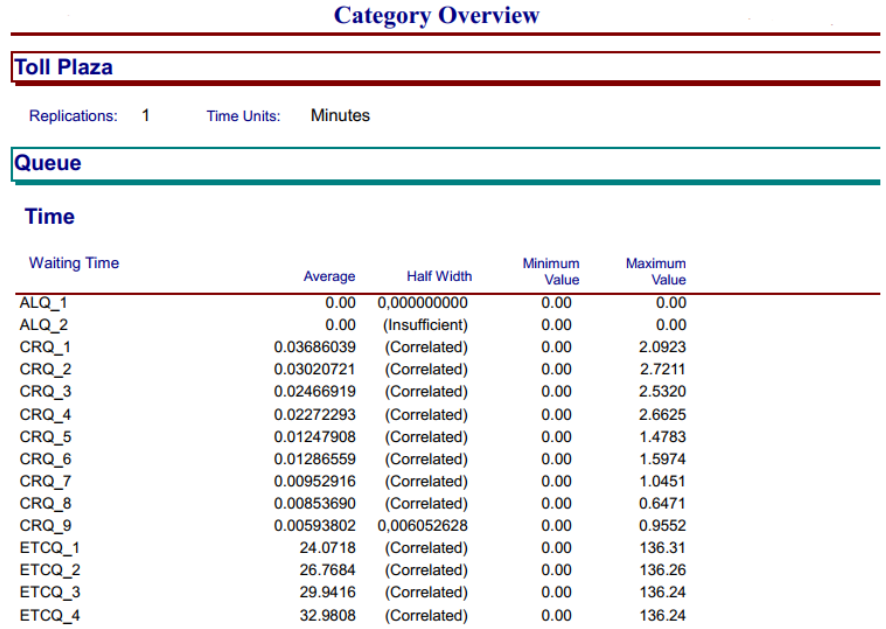

(a) Waiting time

\begin{tabular}{|c|c|c|c|c|}
\hline Number Waiting & Average & Half Width & $\begin{array}{c}\text { Minimum } \\
\text { Value }\end{array}$ & $\begin{array}{c}\text { Maximum } \\
\text { Value }\end{array}$ \\
\hline ALQ_1 & 0.00 & (Insufficient) & 0.00 & 0.00 \\
\hline ALQ_2 & 0.00 & (Insufficient) & 0.00 & 0.00 \\
\hline CRQ_1 & 0.07453990 & (Correlated) & 0.00 & 2.0000 \\
\hline CRQ_2 & 0.05198157 & (Correlated) & 0.00 & 2.0000 \\
\hline CRQ_3 & 0.03541057 & (Correlated) & 0.00 & 2.0000 \\
\hline CRQ_4 & 0.02632073 & (Insufficient) & 0.00 & 2.0000 \\
\hline CRQ_5 & 0.01225376 & (Insufficient) & 0.00 & 1.0000 \\
\hline CRQ_6 6 & 0.00994403 & (Insufficient) & 0.00 & 1.0000 \\
\hline $\mathrm{CRQ}_{7} 7$ & 0.00565794 & (Insufficient) & 0.00 & 1.0000 \\
\hline CRQ_8 & 0.00388310 & (Insufficient) & 0.00 & 1.0000 \\
\hline CRQ_9 & 0.00186800 & (Insufficient) & 0.00 & 1.0000 \\
\hline ETCQ_1 & 330.86 & (Correlated) & 0.00 & 1916.00 \\
\hline ETCQ_2 & 330.74 & (Correlated) & 0.00 & 1916.00 \\
\hline ETCQ_3 & 330.59 & (Correlated) & 0.00 & 1915.00 \\
\hline ETCQ_4 & 330.47 & (Correlated) & 0.00 & 1915.00 \\
\hline
\end{tabular}

(b) Number waiting

Figure 6: Performance indicators: Scenario 3.

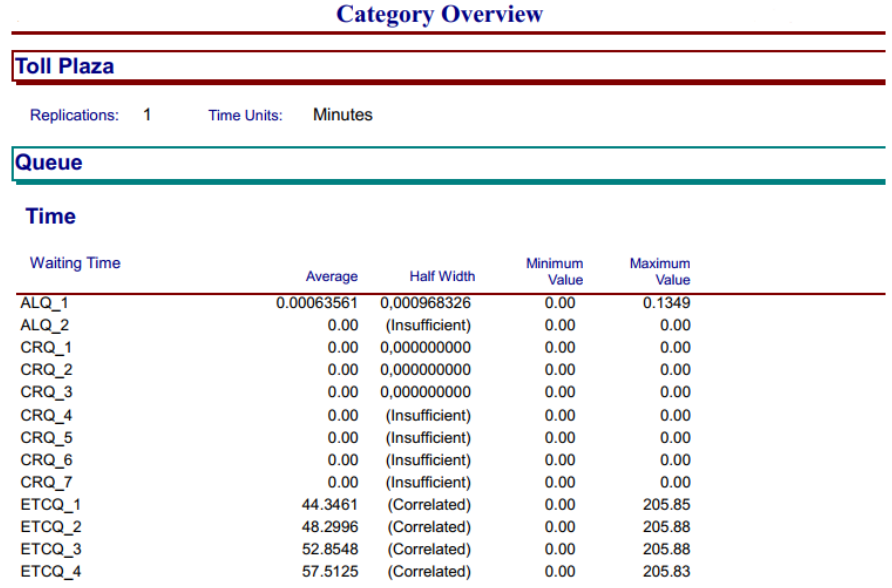

(a) Waiting time

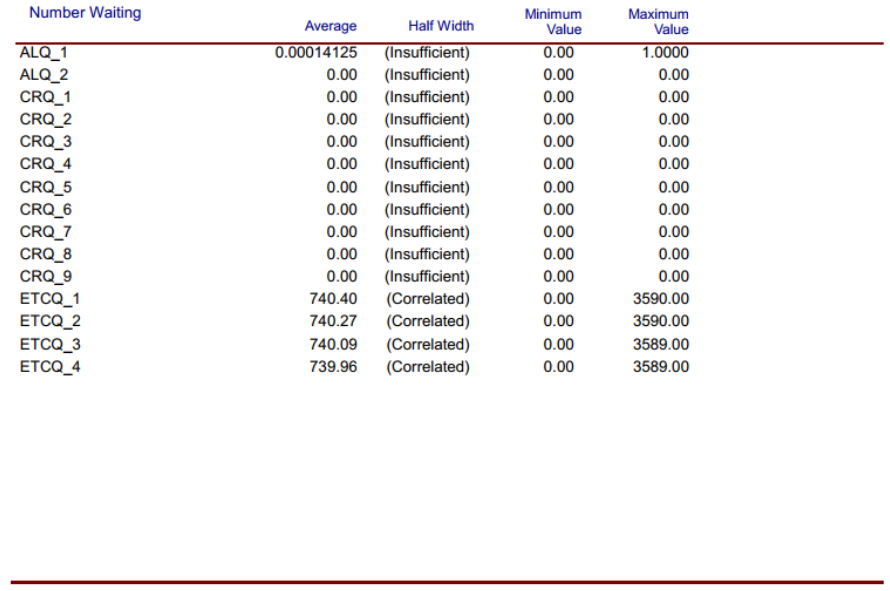

(b) Number waiting

Figure 7: Performance indicators: Scenario 4.

and one automated lane (See figure 8).

Table 2: The experimental design of scenarios

\begin{tabular}{|c|c|c|}
\hline Case study & No of toll booth & $\begin{array}{c}\text { ETC } \\
\text { penetration } \\
\text { rate }\end{array}$ \\
\hline Case-1 & $\begin{array}{c}\text { 9 manual lanes, 4 } \\
\text { ETC lanes, 2 } \\
\text { automated lanes }\end{array}$ & $40 \%$ \\
\hline Case-2 & $\begin{array}{c}\text { 9 manual lanes, 4 } \\
\text { ETC lanes, 2 } \\
\text { automated lanes }\end{array}$ & $60 \%$ \\
\hline Case-3 & $\begin{array}{c}\text { 9 manual lanes, 4 } \\
\text { ETC lanes, 2 } \\
\text { automated lanes }\end{array}$ & $80 \%$ \\
\hline Case-4 & $\begin{array}{c}\text { 9 manual lanes, 4 } \\
\text { ETC lanes, 2 } \\
\text { automated lanes }\end{array}$ & \\
\hline
\end{tabular}

The second scenario: We will consider a tolerable waiting time of 7 minutes and an ETC rate of $60 \%$.

By adjusting the number of booths, the maximum value of total average waiting time obtained is 7 minutes, which happens when the number of active tollbooths is 17: 12 manual lanes, 4 ETC lanes and one automated lane (See figure9).

The third scenario: We will consider a tolerable waiting time of 7 minutes and an ETC rate of $80 \%$.

By adjusting the number of booths, the maximum value of total average waiting time obtained is 5 minutes, which happens when the number of active tollbooths is 13: 6 manual lanes, 6 ETC lanes and one automated lane (See figure 10 ).

The fourth scenario: We will consider a tolerable waiting time of 7 minutes and an ETC rate of $95 \%$.

By adjusting the number of booths, the maximum value of total average waiting time obtained is 1.4 minutes, which happens when the number of active tollbooths is 10: 2 manual lanes, 7 ETC lanes and one automated lane (See figure 11).

From 3 summarizes the main results obtained from the simulation. 


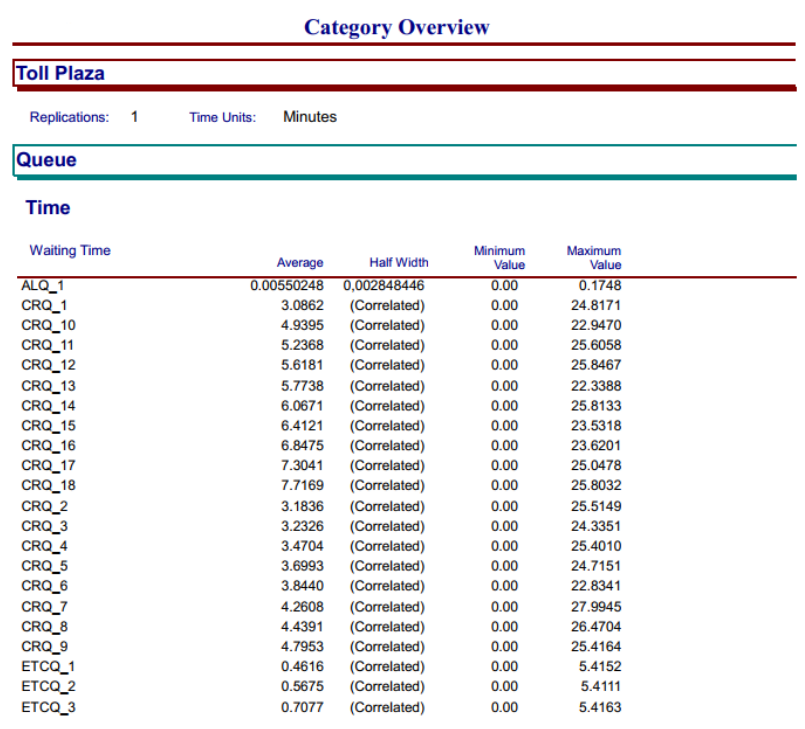

(a) Waiting time
Category Overview

\begin{tabular}{|c|c|c|c|c|}
\hline \multicolumn{5}{|l|}{ Toll Plaza } \\
\hline Replications: 1 & \multicolumn{2}{|c|}{ Minutes } & & \\
\hline \multicolumn{5}{|l|}{ Queue } \\
\hline \multicolumn{5}{|l|}{ Other } \\
\hline Number Waiting & Average & Half Width & $\begin{array}{l}\text { Minimum } \\
\text { Valuve }\end{array}$ & $\begin{array}{l}\text { Maximum } \\
\text { Value }\end{array}$ \\
\hline$\overline{\text { ALQ_1 }}$ & 0.00130684 & (Insufficient) & 0.00 & 1.0000 \\
\hline CRQ_1 & 7.4584 & (Correlated) & 0.00 & 60.0000 \\
\hline CRQ_10 & 7.2652 & (Correlated) & 0.00 & 59.0000 \\
\hline CRQ_11 & 7.2479 & (Correlated) & 0.00 & 59.0000 \\
\hline CRQ_12 & 7.2450 & (Correlated) & 0.00 & 59.0000 \\
\hline CRQ_13 & 7.2173 & (Correlated) & 0.00 & 59.0000 \\
\hline CRQ_14 & $\begin{array}{l}7.2047 \\
7.2175\end{array}$ & (Correlated) & 0.00 & 59.0000 \\
\hline CRQ_15 & 7.1914 & (Correlated) & 0.00 & 59.0000 \\
\hline CRQ_16 & 7.1709 & (Correlated) & 0.00 & 59.0000 \\
\hline CRQ_17 & 7.1773 & (Correlated) & 0.00 & 59.0000 \\
\hline CRQ_18 & 7.1435 & (Correlated) & 0.00 & 59.0000 \\
\hline CRQ_2 & $\begin{array}{l}7.1453 \\
7.4262\end{array}$ & (Correlated) & 0.00 & 60.0000 \\
\hline CRO_- 3 & 7.3945 & (Correlated) & 0.00 & 60.0000 \\
\hline CRO_4 & 7.37370 & (Correlated) & 0.00 & 60.0000 \\
\hline CRQ_5 & 7.3549 & $\begin{array}{l}\text { (Correlated) } \\
\text { (a) }\end{array}$ & 0.00 & 60.0000 \\
\hline CRQ_6 6 & 7.3355 & (Correlated) & 0.00 & 59.0000 \\
\hline $\mathrm{CRO}^{7}$ & 7.3144 & (Correlated) & 0.00 & 59.0000 \\
\hline CRQ_8 & 7.2999 & (Correlated) & 0.00 & 59.0000 \\
\hline CRO_9 & 7.2863 & (Correlated) & 0.00 & 59.0000 \\
\hline ETCQ_1 & 3.6993 & 4,68322 & 0.00 & 65.0000 \\
\hline ETCO_2 & $\begin{array}{l}3.0993 \\
3.5759\end{array}$ & $\begin{array}{l}4,03222 \\
4,64659\end{array}$ & 0.00 & 65.0000 \\
\hline ETCQ_3 & 3.4807 & 4,60773 & 0.00 & 65.0000 \\
\hline
\end{tabular}

(b) Number waiting

Figure 8: Performance indicators: The first scenario.

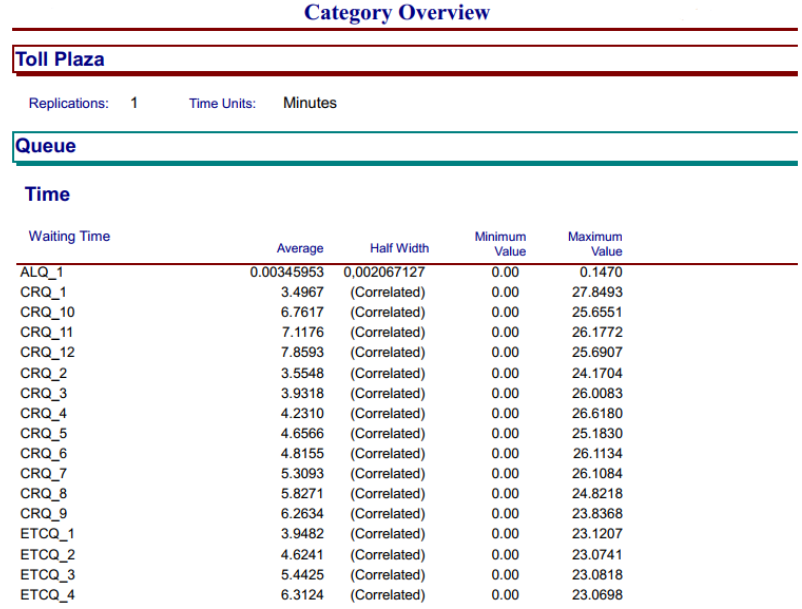

(a) Waiting time

\begin{tabular}{|c|c|c|c|c|}
\hline Number Waiting & Average & Half Width & $\begin{array}{l}\text { Minimum } \\
\text { Value }\end{array}$ & $\begin{array}{l}\text { Maximum } \\
\text { Value }\end{array}$ \\
\hline$\overline{A L Q}$-1 & 0.00078560 & (Insufficient) & 0.00 & 1.0000 \\
\hline $\mathrm{CRQ}_{-}^{-1}$ & 8.0132 & (Correlated) & 0.00 & 64.0000 \\
\hline CRQ10 & 7.7430 & (Correlated) & 0.00 & 63.0000 \\
\hline CRQ_11 & 7.7206 & (Correlated) & 0.00 & 63.0000 \\
\hline CRQ12 & 7.7010 & (Correlated) & 0.00 & 63.0000 \\
\hline CRQ_2 & 7.9761 & (Correlated) & 0.00 & 64.0000 \\
\hline $\mathrm{CRQ}_{3} 3$ & 7.9401 & (Correlated) & 0.00 & 64.0000 \\
\hline CRQ_4 & 7.9038 & (Correlated) & 0.00 & 64.0000 \\
\hline $\mathrm{CRQ}_{5} 5$ & 7.8742 & (Correlated) & 0.00 & 64.0000 \\
\hline CRQ_6 & 7.8553 & (Correlated) & 0.00 & 64.0000 \\
\hline $\mathrm{CRQ}{ }^{7}$ & 7.8164 & (Correlated) & 0.00 & 63.0000 \\
\hline CRQ_8 & 7.7978 & (Correlated) & 0.00 & 63.0000 \\
\hline CRQ_9 & 7.7641 & (Correlated) & 0.00 & 63.0000 \\
\hline ETCQ_1 & 35.6957 & (Correlated) & 0.00 & 278.00 \\
\hline ETCQ_2 & 35.5963 & (Correlated) & 0.00 & 277.00 \\
\hline ETCQ_3 & 35.4861 & (Correlated) & 0.00 & 277.00 \\
\hline $\mathrm{ETCO}_{4} 4$ & 35.3799 & (Correlated) & 0.00 & 277.00 \\
\hline
\end{tabular}

(b) Number waiting

Figure 9: Performance indicators: The second scenario.

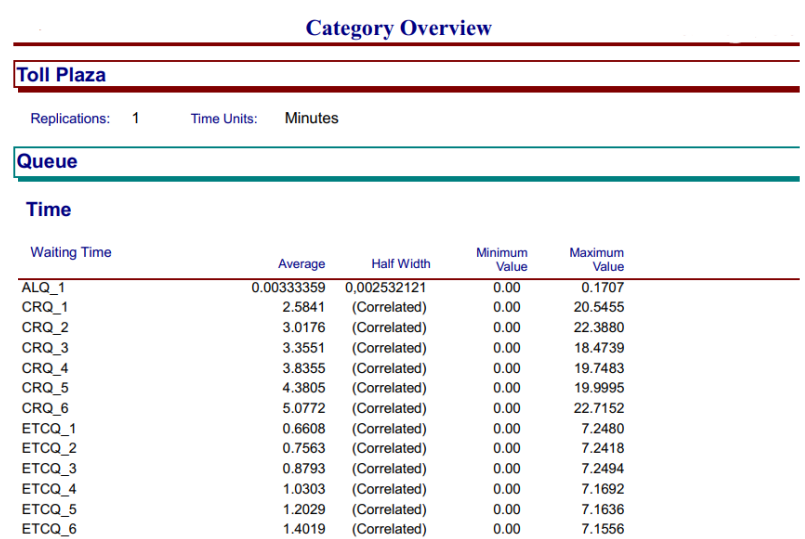

(a) Waiting time

\begin{tabular}{lrcrr} 
Number Waiting & Average & Half Width & $\begin{array}{r}\text { Minimum } \\
\text { Value }\end{array}$ & $\begin{array}{r}\text { Maximum } \\
\text { Value }\end{array}$ \\
\hline ALQ_1 & 0.00078710 & (Insufficient) & 0.00 & 1.0000 \\
CRQ_1 & 5.6420 & (Correlated) & 0.00 & 48.0000 \\
CRQ_2 & 5.5700 & (Correlated) & 0.00 & 48.0000 \\
CRQ_3 & 5.5057 & (Correlated) & 0.00 & 48.0000 \\
CRQ_4 & 5.4496 & (Correlated) & 0.00 & 48.0000 \\
CRQ_5 & 5.4026 & (Correlated) & 0.00 & 48.0000 \\
CRQ_6 & 5.3522 & (Correlated) & 0.00 & 47.0000 \\
ETCQ_1 & 6.0650 & (Correlated) & 0.00 & 87.0000 \\
ETCQ_2 & 6.0136 & (Correlated) & 0.00 & 87.0000 \\
ETC__3 & 5.9448 & (Correlated) & 0.00 & 87.0000 \\
ETCQ_4 & 5.8984 & (Correlated) & 0.00 & 87.0000 \\
ETCQ_5 & 5.8666 & (Correlated) & 0.00 & 86.0000 \\
ETCQ_6 & 5.8307 & (Correlated) & 0.00 & 86.0000
\end{tabular}

(b) Number waiting

Figure 10: Performance indicators: The third scenario. 


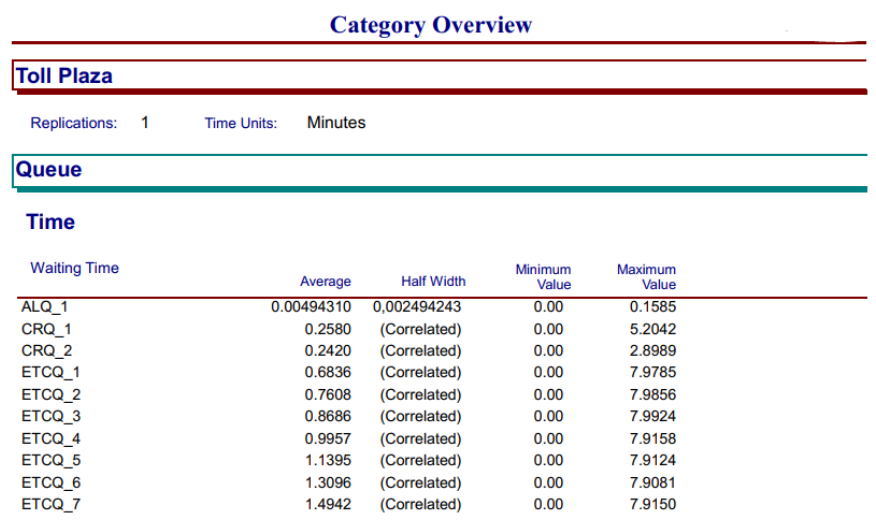

(a) Waiting time

\begin{tabular}{|c|c|c|c|c|}
\hline Number Waiting & Average & Half Width & 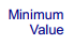 & $\begin{array}{l}\text { Maximum } \\
\text { Valaue }\end{array}$ \\
\hline$\overline{A L Q}$ AL1 & 0.00112936 & (Insufficient) & 0.00 & 1.0000 \\
\hline CRQ 1 & 0.3344 & (Correlated) & 0.00 & 90000 \\
\hline CRQ-2 & 0.2092 & (Correlated) & 0.00 & 9.0000 \\
\hline ETCQ_1 & 6.4671 & (Correlated) & 0.00 & 96.0000 \\
\hline ETCQ_2 & 6.4124 & (Correlated) & 0.00 & 96.0000 \\
\hline ETCQ_3 & 6.3624 & (Correlated & 0.00 & 96.0000 \\
\hline ETCQ_4 & 6.3207 & (Correlated) & 0.00 & 95.0000 \\
\hline ETCQ 5 & 6.2869 & (Correlated) & 0.00 & 95.0000 \\
\hline ETCQ_6 & 6.2504 & (Correlated) & 0.00 & 95.0000 \\
\hline ETCQ7 7 & 6.2281 & (Correlated & 0.00 & 95.0000 \\
\hline
\end{tabular}

(b) Number waiting

Figure 11: Performance indicators: The fourth scenario.

\section{Conclusion}

The benefits resulting from the use of ETC technology was evaluated in this paper. The analysis was accomplished by utilizing collected field data and simulated scenarios using ARENA simulation software. A comparison of different case studies was performed.

Results showed that an optimal toll plaza depends largely on the number of different types of tollbooths and the ETC share. An increase in the rate of ETC have a considerable impact in reducing the total delay caused at the manual lanes, but on the other hand it reduces the efficiency of the ETC lanes as they become gradually saturated with the increasing of its users.

Therefore, under a given time-dependent traffic flow and a set of different ETC rates, several scenarios were considered in order to find the optimal number of tollbooths that provide the best possible service.

As the proportion of the ETC user increases, number of tollbooths, queue length and waiting time are all decreased, resulting in high operating efficiency.

Table 3: Simulation results

\begin{tabular}{|c|c|c|c|}
\hline Scenario & ETC rate & $\begin{array}{c}\text { Optimal number } \\
\text { of tollbooths }\end{array}$ & $\begin{array}{c}\text { Maximum } \\
\text { Average } \\
\text { Waiting Time } \\
\text { Obtained } \\
\text { (min) }\end{array}$ \\
\hline $\begin{array}{c}\text { Scenario- } \\
1\end{array}$ & $40 \%$ & $\begin{array}{c}18 \text { manual lanes, 3 } \\
\text { ETC lanes and one } \\
\text { automated lane }\end{array}$ & 7 \\
\hline $\begin{array}{c}\text { Scenario- } \\
2\end{array}$ & $60 \%$ & $\begin{array}{c}12 \text { manual lanes, } \\
\text { ETC lanes and one } \\
\text { automated lane }\end{array}$ & 7 \\
\hline $\begin{array}{c}\text { Scenario- } \\
3\end{array}$ & $80 \%$ & $\begin{array}{c}\text { 6 manual lanes, 6 } \\
\text { ETC lanes and one } \\
\text { automated lane }\end{array}$ & \\
\hline $\begin{array}{c}\text { Scenario- } \\
4\end{array}$ & $95 \%$ & $\begin{array}{c}\text { 2 manual lanes, } 7 \\
\text { ETC lanes and one } \\
\text { automated lane }\end{array}$ & \\
\hline
\end{tabular}

Conflict of Interest The authors declare no conflict of interest.

\section{References}

[1] Y. Liu, H. Liao, Z. Yu, M. Cai,“Analysis of the Operational Impact of ETC Lanes on Toll Station", in 11th International Conference of Chinese Transportation Professionals (ICCTP), 2011. DOI: 10.1061/41186(421)262

[2] H.M. Al-Deek, A.A. Mohamed, A.E. Radwan, "Operational Benefits of Electronic Toll Collection: Case Study", Journal of Transportation Engineering, 123(6), 467-477, 1997. DOI: 10.1061/(ASCE)0733-947X(1997)123:6(467)

[3] H.M. Al-Deek, A.A. Mohamed, "Simulation and Evaluation of the OrlandoOrange County Expressway Authority (OOCEA) Electronic Toll Collection Plazas Using TPSIM", Florida Department of Transportation Research Center, April 2000.

[4] H.M. Al-Deek, A.A. Mohamed, E.A. Radwan, "New Model for Evaluation of Traffic Operations at Electronic Toll Collection Plazas", Transportation Research Record, 1710(1), 1-10, 2000. DOI: 10.3141/1710-01

[5] Nezamuddin. "Developing microscopic toll plaza model using PARAMICS", MS Thesis, Department of Civil and Environmental Engineering in the College of Engineering and Computer Science at the University Of Central Florida Orlando, Florida, USA, 2006.

[6] L. Jian, D.I.N.G. Jiping, Y.E. Fan, "ETC System Benefit Evaluation and Performance Index System", Journal of Transportation Engineering and Information, 1(1), 75-80, 2003.

[7] P. Tseng, D. Lin, S. Chien, "Investigating the impact of highway electronic toll collection to the external cost: A case study in Taiwan", Technological Forecasting and Social Change, 86, 265-272, 2014. DOI: 10.1016/j.techfore.2013.10.019

[8] N.M.V. Dijk, M.D. Hermans, M.J.G. Teunisse, H. Schuurman, "Designing the Westercheldetunnel toll plaza using a combination of queueing and simulation", In Proceedings of the 31st conference on Winter simulation: Simulation-a bridge to the future, Association for Computing Machinery, New York, NY, USA, 1272-1279, 1999. DOI: 10.1145/324898.325061

[9] M. Burris, E. Hildebrand, "Using microsimulation to quantify the impact of electronic toll collection,’ITE Journal 66(N7), 21-24, 2016.

[10] A.A. Saka, D.K. Agboh, S. Ndiritu, R.A. Glassco, "Estimation of Mobile Emissions Reduction from Using Electronic Tolls", Journal of Transportation Engineering, 127(4), 327-333, 2001. DOI: 10.1061/(ASCE)0733947X(2001)127:4(327)

[11] W.D. Kelton, R.P.Sadowski, D.A. Sadowski, "Simulation with arena", WCB/McGraw-Hill, 1998.

[12] G. Mackinnon, A. Kannan, M. Van Aerde, "Evaluating the impacts of implementing electronic toll collection using INTEGRATION", Towards an Intelligent Transport System. Proceedings of the First World Congress on Applications of Transport Telematics and Intelligent Vehicle-Highway Systems, November 30 - 3 December 1994, Paris, 1994.

[13] E.A. Gordin "Evaluation Of The Potential Benefits To Traffic Operations At A Toll Plaza With Express Etc Lanes." MS Thesis, Department of Civil and Environmental Engineering in the College of Engineering and Computer Science at the University of Central Florida Orlando, Florida, 2004. 